\title{
Mechanical and Electrical Properties of Styrene-Isoprene-Styrene Copolymer Doped with Expanded Graphite Nanoplatelets
}

\author{
Zdenko Špitalský, ${ }^{1}$ Ján Kratochvíla, ${ }^{1}$ Katarína Csomorová, ${ }^{1}$ Igor Krupa, ${ }^{2}$ \\ Manuel P. F. Graça, ${ }^{3}$ and Luis C. Costa ${ }^{3}$ \\ ${ }^{1}$ Polymer Institute, Slovak Academy of Sciences, Dubravska Cesta 9, 84541 Bratislava, Slovakia \\ ${ }^{2}$ Center for Advanced Materials, Qatar University, P.O. Box 2713, Doha, Qatar \\ ${ }^{3}$ I3N and Physics Department, University of Aveiro, 3810-193 Aveiro, Portugal
}

Correspondence should be addressed to Zdenko Špitalský; upolspiz@savba.sk

Received 6 March 2015; Accepted 9 July 2015

Academic Editor: Nay Ming Huang

Copyright (C) 2015 Zdenko Špitalský et al. This is an open access article distributed under the Creative Commons Attribution License, which permits unrestricted use, distribution, and reproduction in any medium, provided the original work is properly cited.

\begin{abstract}
The molecular dynamics of a triblock copolymer and of expanded graphite nanoplatelets were investigated. Composites were prepared using the solution technique. The effects of filler addition and of filler-matrix interactions were investigated using dielectric relaxation spectroscopy (DRS) and dynamic mechanical analysis (DMA). Only one relaxation was observed by DRS, which was associated with the relaxation of the main polymer chain. Both DRS and DMA demonstrated that the addition of the filler does not cause a significant change in either the temperature of the relaxation or its activation energy, which suggests the presence of weak interactions between the filler and matrix. The storage modulus of the composites increased with increasing filler content. The composite containing $8 \%$ filler exhibited a storage modulus increase of approximately $394 \%$ in the rubber area. Using the DC electrical conductivity measurements, the electrical percolation threshold was determined to be approximately $5 \%$. The dielectric permittivity and conductivity in the microwave region were determined, confirming that percolating behavior and the critical threshold concentration.
\end{abstract}

\section{Introduction}

Graphene is a flat monolayer of carbon atoms that are tightly packed into a two-dimensional (2D) carbon honeycomb lattice. Recently, graphene has attracted considerable attention due to its high surface area, low density, and electrical and mechanical properties [1-7]. The incorporation of graphene particles into polymer matrices promises to produce composites that possess unusual properties [8-16].

The electrical conductivity of an insulating polymer can be enhanced by adding different conducting particles, such as carbon [1-15], metals, or even another conducting polymer [16]. A low electrical percolation threshold can also be achieved with graphene sheets. An electrical percolation threshold of $0.05 \mathrm{wt} . \%$ was observed in the polyethyleneterephthalate matrix [17]. Additionally, an improvement in mechanical properties was observed in thermoplastic polyurethane, and the incorporation of $3 \mathrm{wt} \%$ of ultrathin graphene sheets improves the storage modulus (by $300 \%$ ), shear viscosity (by $150 \%$ ), and thermal stability of the material. Further improvement was observed when the oxidized form of graphene was applied; this improvement was likely due to improved chemical interactions [18]. Moreover, graphene-based composites have been reported to possess a novel behavior: photoactuation [19]. Compared to other carbon-based fillers, the graphene-based nanopellets exhibited the best actuation behavior [20]. This result highlights the potential of these elastomer-based graphene composites.

The physical properties of a composite are always determined by the employed processing technique. Compared to the solution mixing method, the in situ preparation of graphene oxide/polyurethane composites resulted in an 
improvement in the modulus. The observed reinforcing effect was attributed to the improved interactions obtained during this in situ method [21]. Similar results were also obtained in the thermoplastic polyurethane matrix [22]; however only a weak reinforcement effect has been reported in polyethylene matric [23]. The physical properties of the grapheme-polymer composites depend also highly on the degree of cross-linking and the final morphology [24]. This result can be attributed to the decreased aspect ratio of the filler, as it can emerge either in a wrinkled conformation of the filler [25] or due to particle attrition during mixing [26]. It was also reported that the sonication of expanded graphite in a viscous solution enables the further separation of graphene platelets into smaller nanometer-sized platelets [27]. As the expanded graphene layers are intercalated by polymer chains, it is hypothesized that the sonicated expanded graphene possesses a larger number of smaller platelets and therefore serves as a more efficient nanofiller [28].

The need to protect electronic components against electromagnetic interference is very important, particularly at microwave frequencies where wireless communications occur. The effects of electromagnetic interference can be decreased by positioning a shielding material between the source of the electromagnetic field and the electronic component. Graphene composites are a good possibility for achieving that objective. Then, microwave dielectric properties were measured using the resonant cavity method $[29,30]$. To the best of our knowledge there is only one work concerning microwave spectroscopy study of graphene-based elastomer composite materials when the microwave permittivity of styrene-butadiene rubber composite was unaffected by strain up to $8 \%$ [31].

Therefore, in this study, expanded graphite obtained using the solution sonication technique was employed. In this paper, the results from a study on the molecular dynamics of a styrene-isoprene-styrene and graphene sheet composite are presented. The composites were prepared using the solution technique, and their percolation behaviors, impedance spectra, and mechanical properties were characterized.

\section{Materials and Methods}

2.1. Materials. GFG50 expanded graphite particles, with an average size of $50 \mu \mathrm{m}$, were obtained from SGL Technologies GmbH, Germany. Kraton D1165 PT (a linear triblock copolymer based on styrene and isoprene with a polystyrene content of 30\%) was purchased from Kraton Performance Polymers Inc. Toluene with a p.a. purity was purchased from Sigma-Aldrich and was used without further purification.

A dispersion of GFG50 in $50 \mathrm{~mL}$ of toluene was produced by sonication in an ultrasonic bath for 20 minutes, followed by mixing with a polymer solution $(2 \mathrm{~g}$ of polymer was dissolved in $20 \mathrm{~mL}$ of toluene under rigorous stirring). The thin films were casted onto a Teflon array. The thin films with a nanofiller concentration of up to $10 \mathrm{wt}$. $\%$ exhibited an average thickness of approximately $400 \mu \mathrm{m}$.
2.2. Polymer Characterization. XRD analysis was conducted using a Bruker D8 DISCOVER diffractometer equipped with an $\mathrm{X}$-ray tube with a rotating $\mathrm{Cu}$ anode operating at $12 \mathrm{~kW}$. All of the measurements were performed using a parallel beam geometry with a parabolic Goebel mirror positioned in the primary beam.

The X-ray diffraction patterns were recorded using a grazing incidence setup with an angle of incidence $2^{\circ}$. The surface morphologies were examined using scanning electron microscopy with a dual beam (FIB/SEM) Microscope Quanta 3D 200i (FEI). The free surface and the cross sections of these materials were investigated. All of the specimens were sputter coated with a thin layer of gold prior to examination.

TGA measurements were performed using a Mettler Toledo TGA/SDTA 851 instrument in a nitrogen flow $(30 \mathrm{~mL} / \mathrm{min})$ using a heating rate of $10^{\circ} \mathrm{C} / \mathrm{min}$ over the temperature range from $25^{\circ} \mathrm{C}$ to $800^{\circ} \mathrm{C}$. Indium and aluminum were used for temperature calibration. The amount of sample used was $2 \mathrm{mg}$. Two parallel runs were performed for each sample.

Viscoelastic measurements were performed using a TA Instruments DMA Q800 dynamic mechanical analyzer. Samples with uniform shapes were measured in the module tensile multifrequency strain at $10 \mathrm{~Hz}$ and a strain amplitude of $5 \mu \mathrm{m}$. The loss tangent $(\tan \delta)$ and storage modulus were obtained from $-100^{\circ} \mathrm{C}$ to $130^{\circ} \mathrm{C}$ using a heating rate of $2^{\circ} \mathrm{C} / \mathrm{min}$.

For the electrical measurements of the samples, contacts were made by painting both sides of the polymer sample with silver paste, simulating a parallel plate capacitor with a surface area of $1 \mathrm{~cm}^{2}$ and a distance between electrodes of approximately $0.4 \mathrm{~mm}$.

DC conductivity measurements were conducted using the standard two contacts with the guard method, using a Keithley 617 Electrometer, at temperatures between $-110^{\circ} \mathrm{C}$ and $90^{\circ} \mathrm{C}$ in an inert atmosphere.

Dielectric measurements were performed using an Agilent 4294A Precision Impedance Analyzer for frequencies between $40 \mathrm{~Hz}$ and $2 \mathrm{MHz}$. The general approach is to apply an electrical stimulus and to observe the response of the material. It is then assumed that the properties of the electrodematerial system are time invariant, which is an important assumption for the measurement method. The amplitude of the applied voltage was $1 \mathrm{~V}$. From a practical point of view, dielectric spectroscopy can provide a measurement of the complex permittivity, $\varepsilon^{*}(\omega)=\varepsilon^{\prime}(\omega)-i \varepsilon^{\prime \prime}(\omega)$, or derived quantities related to it, such as the dielectric modulus, $M=\varepsilon^{-1}$. The macroscopic properties, such as impedance, $Z^{*}(\omega)=Z^{\prime}(\omega)-i Z^{\prime \prime}(\omega)$, or admittance, $Y=Z^{-1}$, can also be obtained. The interrelations between these quantities are simple when their geometric parameters (shape, size, and thickness) are known. In our case, the measured values were used to calculate the dielectric complex modulus $\left(M^{*}\right)$ using a parallel RC (Resistance-Capacitor) model of the sample. The estimated relative errors on both the real and imaginary parts of the complex permittivity were less than $2 \%$.

For the microwave dielectric measurements, the resonant cavity method at $2.7 \mathrm{GHz}$ was used. The samples used were 


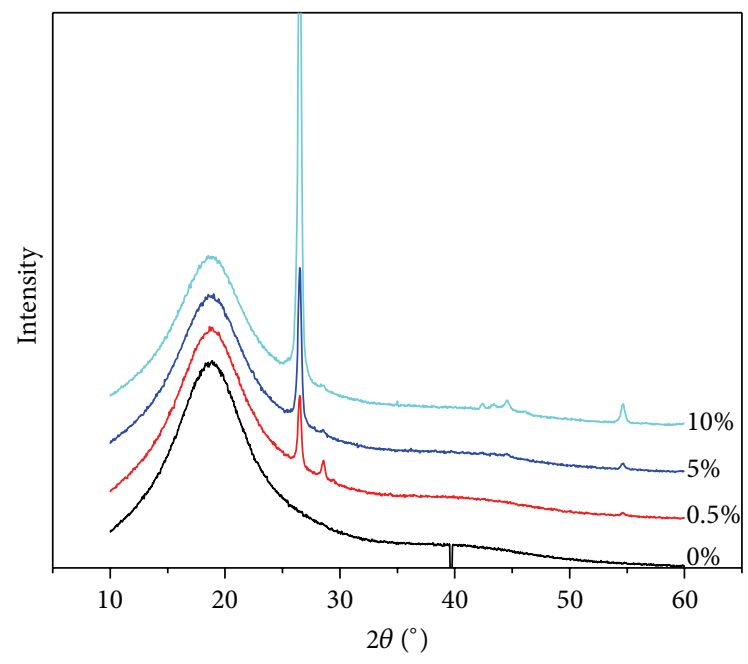

FIGURE 1: WAXS patterns of different samples; neat polymer matrix $(0 \%)$ and three different composites with 0.5 ; 5 ; and 10 wt.\% of filler, respectively.

prepared as cylinders with a height of $8 \mathrm{~mm}$ and a diameter of $4 \mathrm{~mm}$. In this method, the shift in the resonant frequency of the cavity, $\Delta f$, caused by the insertion of a sample in a cavity sample, which is related to the real part of the complex permittivity, $\varepsilon^{\prime}$, and the change in the inverse of the quality factor of the cavity, $\Delta(1 / Q)$, which is associated with the imaginary part, $\varepsilon^{\prime \prime}$, were measured. The mathematical formalism is simple when we consider only the first-order perturbation in the electric field caused by the sample [32]:

$$
\begin{gathered}
\varepsilon^{\prime}=K \frac{\Delta f}{f_{0}} \frac{V}{v}+1 \\
\varepsilon^{\prime \prime}=\frac{K}{2} \Delta\left(\frac{1}{Q}\right) \frac{V}{v},
\end{gathered}
$$

where $K$ is a constant related to the depolarization factor, which depends upon the geometric parameters; $f_{0}$ is the resonance frequency of the cavity; $v$ is the volume of the sample; and $V$ is the volume of the cavity. By using a sample with a known permittivity as a reference, it is possible to calculate the constant $K$. In this case, a PTFE sample with the same shape and dimensions of the samples was used as a reference. These measurements were performed using an Agilent $8753 \mathrm{D}$ Network Analyzer coupled to a $2.7 \mathrm{GHz}$ cavity resonator.

\section{Results and Discussion}

Figure 1 shows the WAXS patterns of different samples. In this figure, 4 lines can be observed for the neat polymer and for 3 composites with different concentrations of nanofiller $(0.5,5$, and $10 \mathrm{wt} . \%)$. The WAXS pattern of the neat polymer matrix contains only one broad peak at approximately $2 \Theta=$ $18.5^{\circ}$. The addition of expanded graphite introduced a new peak at $2 \Theta=26.5^{\circ}$, corresponding to the 002 reflection peak of pure graphite. The intensity of this peak increased as the concentration of GFG50 in the sample increased. No other peaks at lower $2 \Theta$ angles were observed, which indicates no exfoliation to longer distances between individual layers of graphite. This scattering profile corresponds to that of the neat matrix polymer with separate phase (microcomposite) [10]. However, we believe that the sonication step allowed for further separation of graphite platelets to individual graphene sheets, as observed in the scanning electron micrographs of the composites. Because the concentration of graphene sheets is significantly lower than the concentration of expanded graphite particles, which have the dominant peak in the WAXS pattern, no related signal was observed. In addition, peaks of the graphene sheets can also be covered by the broad peak of the amorphous polymer at $2 \Theta=18.5^{\circ}$.

As shown in Figure 2, the nanocomposite surface is not completely flat. This slight waviness was created during the evaporation of the solvent. Small graphene particles (white lines, sizes up to $10 \mu \mathrm{m}$ in length but only few nanometers in thickness) are observed at the surface and are oriented out from the surface. The entire surface is homogeneous for all of the samples, with the same texture. As indicated by the cross-sectional area, this composite is homogeneous through the entire thickness without preferred sedimentation at one side; however, drying the free-standing solvent-casted films required a few hours. Therefore, the distribution of graphene particles is isotropic, meaning that the nanofiller was homogeneously separated in the solvents and that the addition of polymer solution caused the filler to be covered with polymer chains, which prevented their restacking. The starting carbon filler dimension was approximately $50 \mu \mathrm{m}$, and its thickness after sonication is at the nanometer scale, which is evidence that the sonication process exfoliated large graphite particles to thinner ones [33].

Thermogravimetric analysis (TGA) was performed under an inert atmosphere to avoid oxidation processes. As observed from the TGA curves (Figure 3), the neat polymer is stable up to $310^{\circ} \mathrm{C}$, when rapid thermal degradation began. At $T_{50}=391^{\circ} \mathrm{C}, 50 \mathrm{wt} . \%$ of the polymer is decomposed. The entire neat polymer is decomposed at $471^{\circ} \mathrm{C}$. The addition of expanded graphite has only a weak effect on thermal stability; however expanded graphite could act as fire retardant [34]. The onset of thermal degradation is the same as that for the neat polymer. $T_{50}$ value is only slightly shifted by approximately $11^{\circ} \mathrm{C}$ to higher temperatures up to $402^{\circ} \mathrm{C}$ (the value increased as the content of nanofiller increased). The thermal degradation of the composites was completed at the same temperature as for the neat polymer matrix. Only the amount of residue increased as the content of GFG50 particles increased (graphite cannot be removed by combustion under a nitrogen atmosphere at this low temperature).

Figure 4 shows the storage modulus and $\tan \delta$ of the neat polymer matrix curve. The values of the measured properties at selected temperatures are presented in Table 1.

As shown, there are no significant changes in the value of the glass transition temperature between the neat material and composites. The first transition is close to $-40^{\circ} \mathrm{C}$. This transition is caused by the isoprene part of the SIS block copolymer. The second transition caused by the styrene part of the copolymer occurs at an average temperature of $110^{\circ} \mathrm{C}$ 


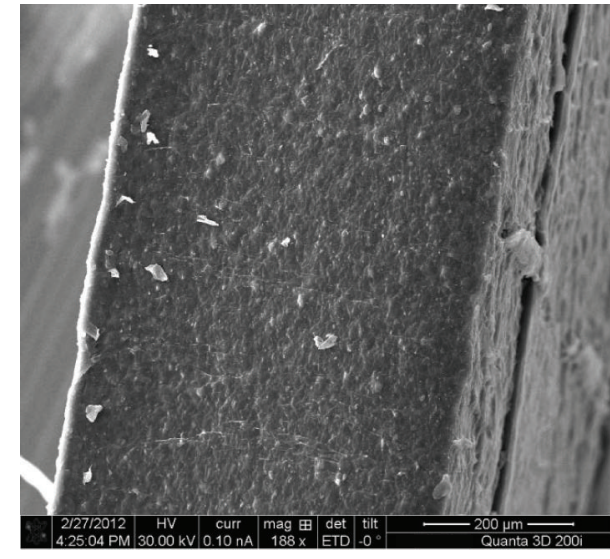

(a)

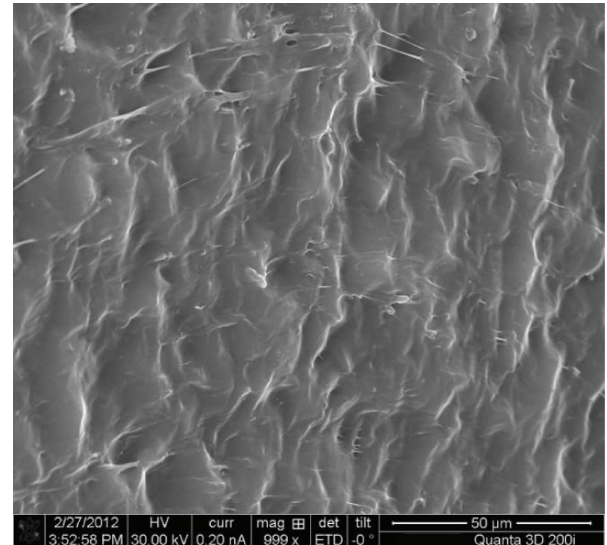

(b)

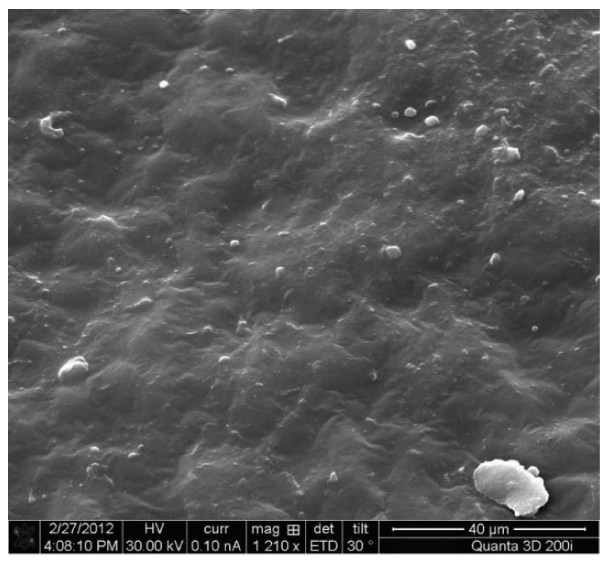

(c)

FIGURE 2: SEM images of GFG50 in Kraton: (a) cross-sectional area of the whole composite for 5 wt.\% GFG50; (b) detailed view of crosssectional area; (c) surface area of nanocomposite.

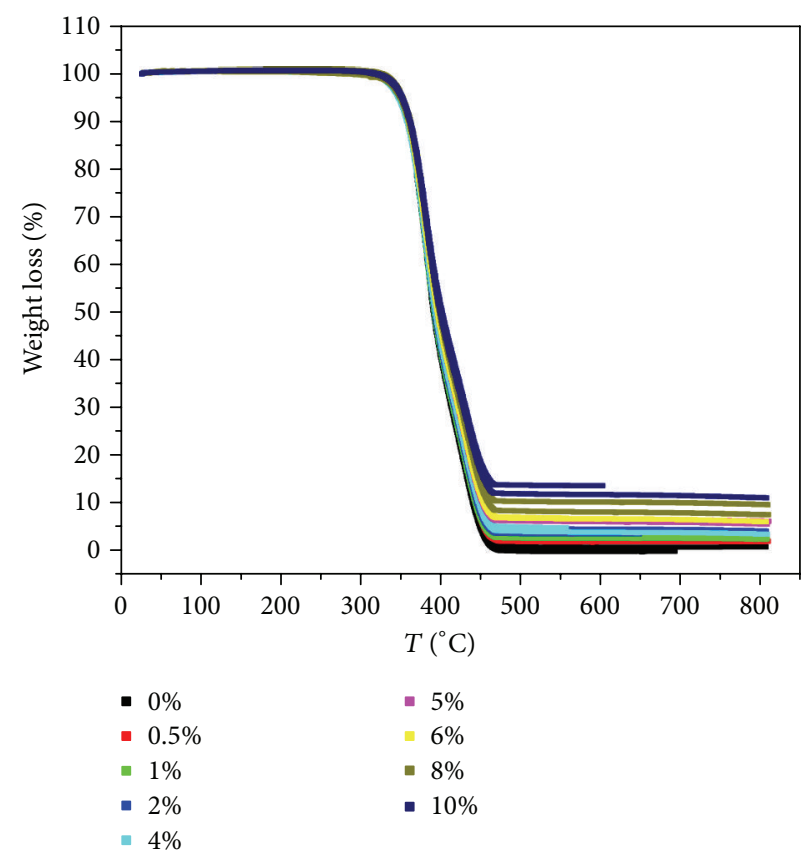

FIGURE 3: TGA curves for all samples. 
TABLE 1: Summary of the thermal and mechanical properties obtained from DMA measurements.

\begin{tabular}{|c|c|c|c|c|c|c|c|c|c|c|c|c|}
\hline$x$ & $T_{g 1}$ by $\tan \delta\left({ }^{\circ} \mathrm{C}\right)$ & $\mathrm{SD}$ & $T_{g 2}$ by $\tan \delta\left({ }^{\circ} \mathrm{C}\right)$ & SD & $E_{-100^{\circ} \mathrm{C}}^{\prime}(\mathrm{MPa})$ & SD & $E_{25^{\circ} \mathrm{C}}^{\prime}(\mathrm{MPa})$ & SD & $E_{50^{\circ} \mathrm{C}}^{\prime}(\mathrm{MPa})$ & SD & $E_{80^{\circ} \mathrm{C}}^{\prime}(\mathrm{MPa})$ & SD \\
\hline 0 & -39.8 & 0.2 & 110.7 & 1.8 & 2796.5 & 400.9 & 5.4 & 0.2 & 4.5 & 0.3 & 3.6 & 0.1 \\
\hline 0.5 & -39.7 & 0.4 & 111.0 & 1.7 & 1228.9 & 477.4 & 4.2 & 1.6 & 3.1 & 1.4 & 2.3 & 1.2 \\
\hline 1.0 & -40.4 & 1.0 & 110.8 & 1.7 & 3256.5 & 580.5 & 6.7 & 2.5 & 5.5 & 2.7 & 4.2 & 2.4 \\
\hline 2.0 & -39.3 & 1.4 & 111.6 & 0.4 & 3471.5 & 297.7 & 8.4 & 1.7 & 5.5 & 3.0 & 4.8 & 2.1 \\
\hline 4.0 & -38.3 & 3.1 & 109.9 & 0.9 & 3612.0 & 596.8 & 12.3 & 1.4 & 10.2 & 0.3 & 7.8 & 0.4 \\
\hline 5.0 & -39.4 & 0.9 & 111.3 & 0.8 & 3561.0 & 287.1 & 12.3 & 1.5 & 10.4 & 1.1 & 8.8 & 0.2 \\
\hline 6.0 & -39.5 & 0.8 & 110.5 & 1.3 & 3889.5 & 805.4 & 14.9 & 0.3 & 11.9 & 1.3 & 9.3 & 1.0 \\
\hline 8.0 & -38.8 & 0.1 & 110.6 & 1.5 & 4728.5 & 238.3 & 26.7 & 0.9 & 21.9 & 2.4 & 15.4 & 4.6 \\
\hline 10.0 & -40.2 & 1.1 & 107.3 & 1.6 & 3505.0 & 1513.2 & 26.5 & 3.7 & 25.3 & 3.4 & 18.4 & 4.9 \\
\hline
\end{tabular}

SD: standard deviation.

$T_{g}$ : glass transition temperature.

$E^{\prime}$ : storage modulus at selected temperature.

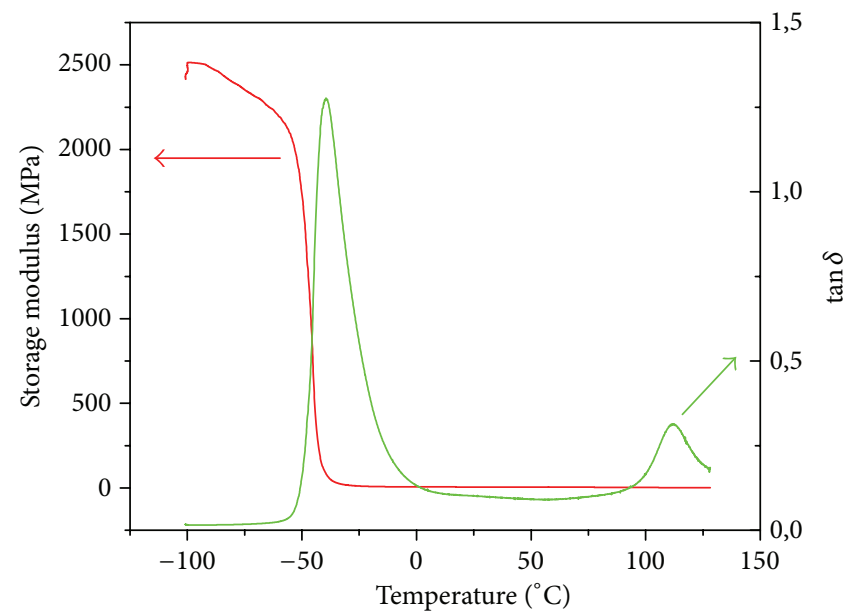

FIGURE 4: Temperature dependence of storage modulus and $\tan \delta$ for neat polymer matrix.

[30]. This behavior suggests very poor interactions between the filler and polymer chains; however an increase of $6^{\circ} \mathrm{C}$ in the PS glass transition temperature was previously observed for functionalized graphene sheets in SIS copolymer [35].

The storage modulus values exhibit an increasing trend at all testing temperatures as the content of GFG50 increases. The most significant reinforcement effect was observed for the sample with $8 \mathrm{wt} \%$ nanofiller, in which the storage modulus $E^{\prime}$ was increased by $69 \%$ to $4.7 \mathrm{GPa}$ in the glass area and by $394 \%$ to $26.7 \mathrm{MPa}$ in the rubber area (at $25^{\circ} \mathrm{C}$ ). The mechanical properties of SIS copolymer with graphene particles were also studied by Ansari et al. in tensile mode [36] when the reinforcement was observed with increasing concentration of filler up to $1 \mathrm{wt} . \%$ and then the decrease of modulus proceeded for higher concentrations.

Figure 5 presents the DC electrical conductivity as a function of the filler concentration at $27^{\circ} \mathrm{C}(300 \mathrm{~K})$. At low concentrations, the small increase in the conductivity of the composite can be attributed to the mobility of a small number of charged particles through the system without a continuous conductive path. At the percolation threshold concentration (5 wt.\%), the conductivity sharply increases due to the formation of a continuous conductive path

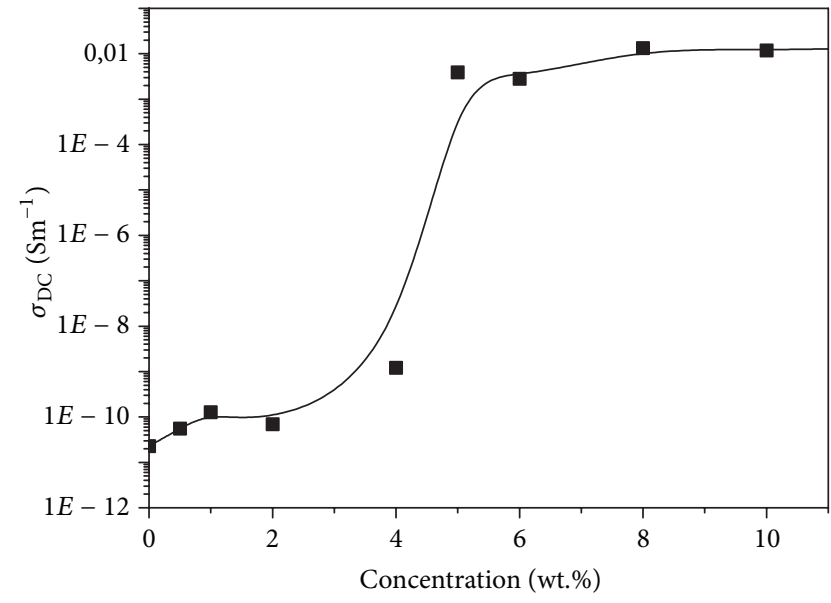

FIGURE 5: DC electrical conductivity $\sigma_{\mathrm{DC}}$ as a function of the filler concentration at $27^{\circ} \mathrm{C}(300 \mathrm{~K})$.

developed in the polymer matrix, and finally, at higher concentrations, the further addition of filler has a marginal effect on the conductivity. The value of percolation threshold is significantly higher than for other polymer composites 


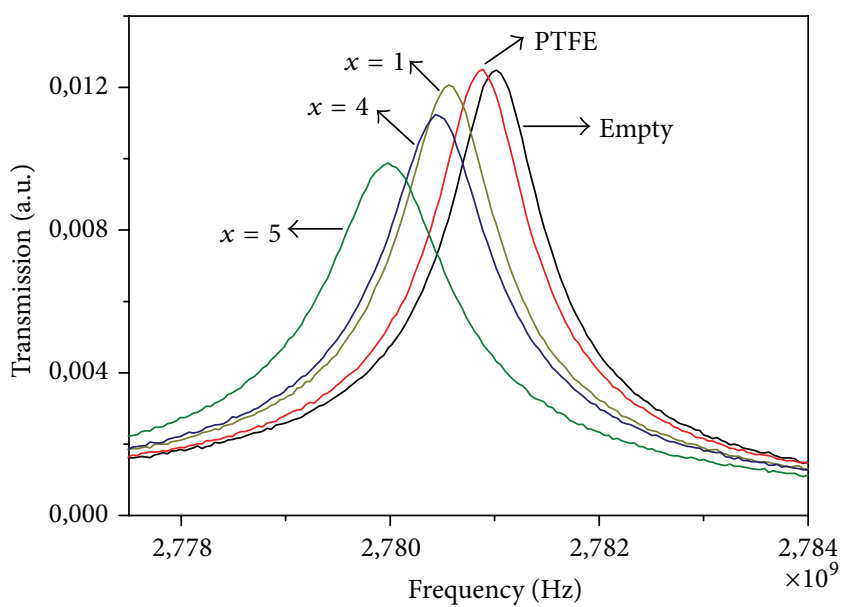

FIGURE 6: Transmission of the $2.7 \mathrm{GHz}$ resonant cavity, with the empty cavity and with different samples, that is, PTFE and copolymer matrix with $1 \mathrm{wt} . \%, 4 \mathrm{wt} . \%$, and $5 \mathrm{wt} . \%$ conducting fillers.

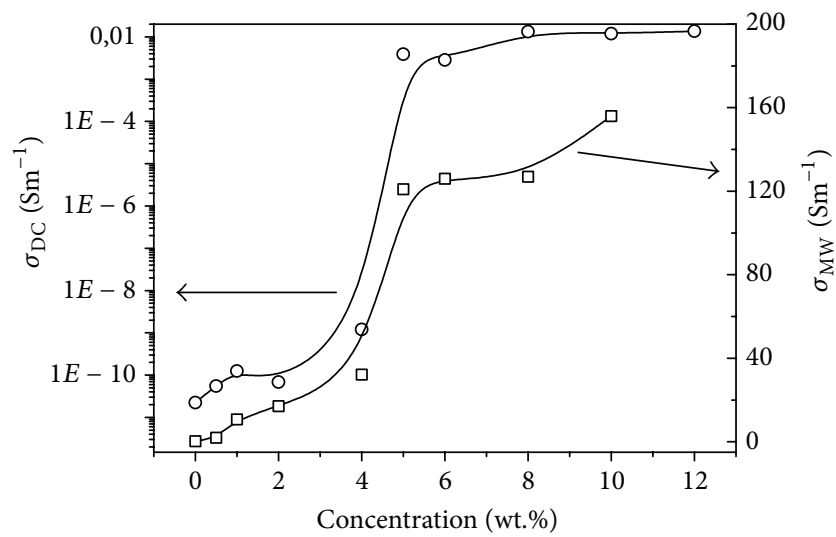

Figure 7: Conductivity at microwave frequencies $\left(\sigma_{\mathrm{MW}}\right)$ at $27^{\circ} \mathrm{C}$ $(300 \mathrm{~K})(\square)$. The DC conductivity $(\circ)$ is also included for comparison $\left(\sigma_{\mathrm{DC}}\right)$.

with graphite nanoplatelets $[17,37]$ but is affected by low interaction between the filler and the polymer matrix caused by microstructure of expanded graphite particles as was observed on WAXS [16].

The percolation behavior can also be observed in the AC conductivity and permittivity measurements. Figure 6 shows the transmission of the $2.7 \mathrm{GHz}$ resonant cavity, with the empty cavity and with different samples, that is, PTFE and copolymer matrix with concentration $1 \mathrm{wt} . \%, 4 \mathrm{wt} . \%$, and $5 \mathrm{wt} . \%$ conducting fillers. It can be observed that the highest perturbation is observed for concentration $5 \mathrm{wt} . \%$, where the percolation path is formed. This perturbation corresponds to highest real and imaginary parts of the complex permittivity.

Using the relation

$$
\sigma_{\mathrm{AC}}=\varepsilon^{\prime \prime} 2 \pi f \varepsilon_{0},
$$

it is possible to calculate the conductivity at microwave frequencies, which is shown in Figure 7 (open squares), at $T=$ $27^{\circ} \mathrm{C}(300 \mathrm{~K})$, in which the DC conductivity is included for comparison (open circles).

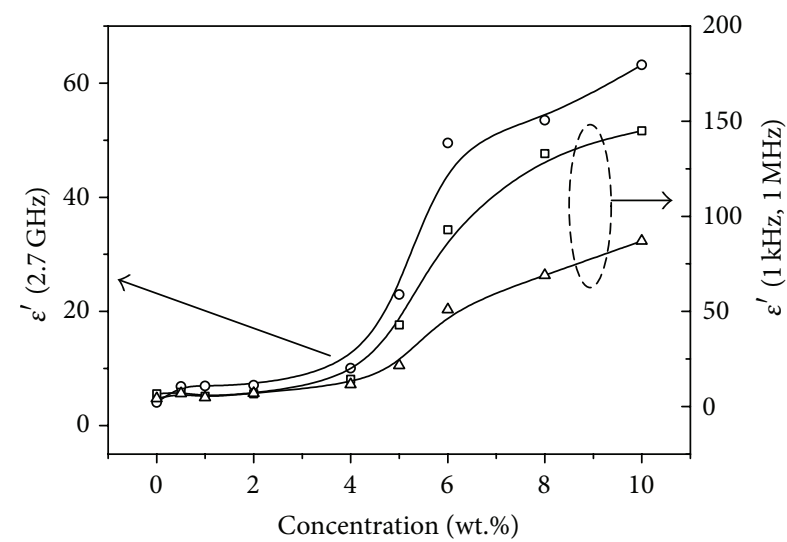

FIGURE 8: Dielectric constants measured at several frequencies ( $\circ$ at $\mathrm{GHz}, \square$ at $\mathrm{kHz}$, and $\triangle$ at $\mathrm{MHz}$ ) at a constant temperature of $27^{\circ} \mathrm{C}$ $(300 \mathrm{~K})$.

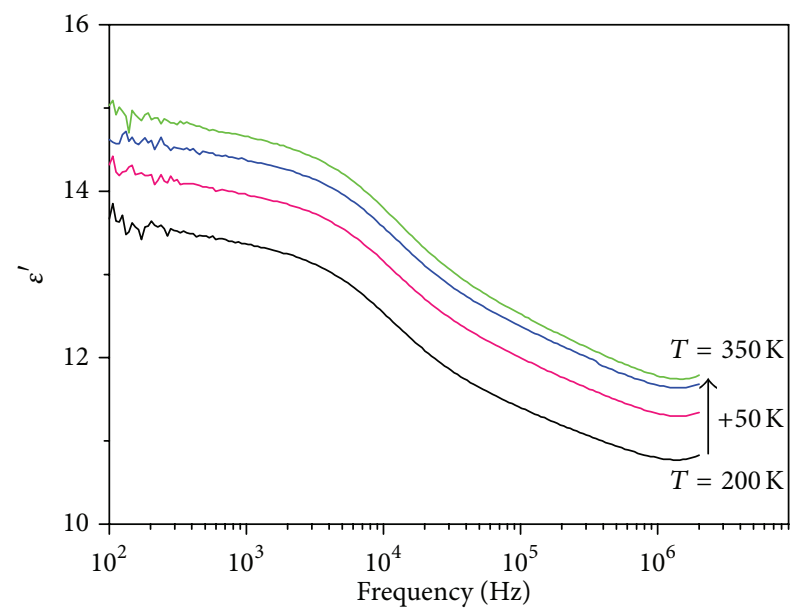

FIGURE 9: Real part of the complex permittivity for a sample with concentration $5 \mathrm{wt} . \%$ at different temperatures.

The dielectric permittivity measurements at microwave frequencies show the same phenomena. The dielectric constants measured at several frequencies and at a constant temperature of $27^{\circ} \mathrm{C}(300 \mathrm{~K})$ are shown in Figure 8.

The literature about influence of graphene on the microwave properties of the elastomeric composites is very rare. The natural rubber $[38,39]$, epoxy [40], or styrenebutadiene rubber based nanocomposites [31] were studied.

Figures 9 and 10 present the real and imaginary parts of the complex permittivity, $\varepsilon^{*}(\omega)=\varepsilon^{\prime}(\omega)-i \varepsilon^{\prime \prime}(\omega)$, for a sample with concentration of filler $5 \mathrm{wt} . \%$ for different temperatures, in which a relaxation process is clearly observed. The peak in the imaginary part and the inflection in the real part of the complex permittivity do not considerably change with temperature. This behavior is observed for all of the samples, including the pure copolymer sample, indicating that this relaxation process is due to the copolymer chains.

Figure 11 presents the Cole-Cole plot of the complex permittivity for the same sample at different temperatures. The observed relaxation has a shape of decentered semicircles 


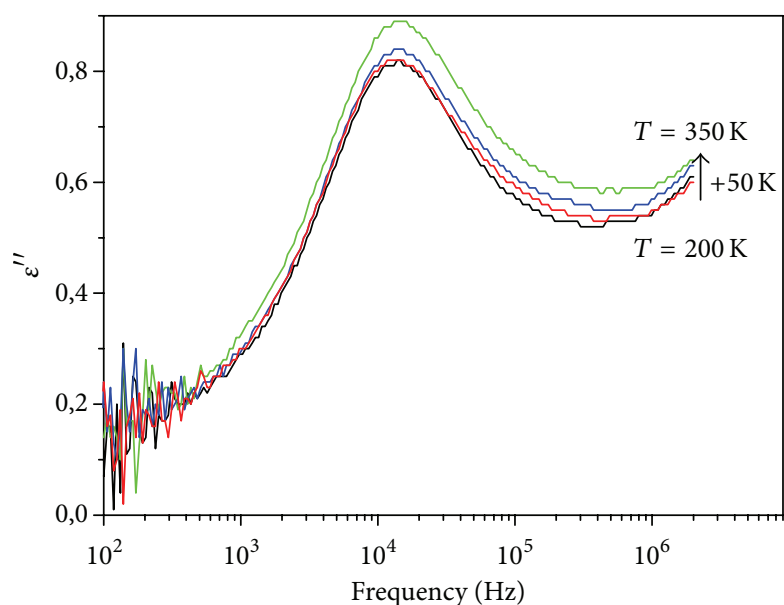

FIGURE 10: Imaginary part of the complex permittivity for a sample with concentration $5 \mathrm{wt}$.\% at different temperatures.

with their center situated below the abscissa axis for all of the temperatures and for all of the samples. This profile indicates that simple exponential decay, corresponding to a Debye relaxation, is not appropriate for describing the relaxation phenomenon and should be replaced by an empirical model, such as the Cole-Cole model

$$
\varepsilon^{*}(\omega)=\varepsilon_{\infty}+\frac{\Delta \varepsilon}{1+(i \omega \tau)^{1-\alpha}} .
$$

In this model, which is a modification of the Debye equation, $\varepsilon_{\infty}$ is the relaxed dielectric constant, $\Delta \varepsilon$ is the dielectric relaxation strength $\left(\Delta \varepsilon=\varepsilon_{0}-\varepsilon_{\infty}\right), \tau$ is the relaxation time, and $\alpha$ is a parameter between 0 and 1 that reflects the dipole interaction or the complexity of the system. The inset of Figure 11 shows the fit for $T=350 \mathrm{~K}$. The calculated values of $\alpha$, approximately 0.26 and independent of temperature and filler concentration, show that the system is very complex and far from the Debye model that corresponds to $\alpha=0$. The relaxation frequency, $f_{r}=1 / 2 \pi \tau$, can be expressed by the well-known Arrhenius relation as

$$
f_{r} \propto \exp \left[-\frac{E_{a}}{k T}\right],
$$

where $T$ is the absolute temperature and $k$ is the Boltzmann constant. The activation energy, $E_{a}$, is practically independent of the filler concentration, with a value of $3.5 \mathrm{meV}$, suggesting that the filler does not interact or only weakly interacts with the chain segments of the macromolecules in the copolymer. Furthermore, this result also suggests that there is poor bonding between the polymer matrix and the conducting nanoparticles. Stronger interactions between the graphene filler and polymer matrix should be introduced by surface modification of graphene particles [41], which will be the aim of our future research.

\section{Conclusion}

Percolation behavior was observed with a critical concentration of approximately $5 \mathrm{wt} . \%$ of conducting filler. This

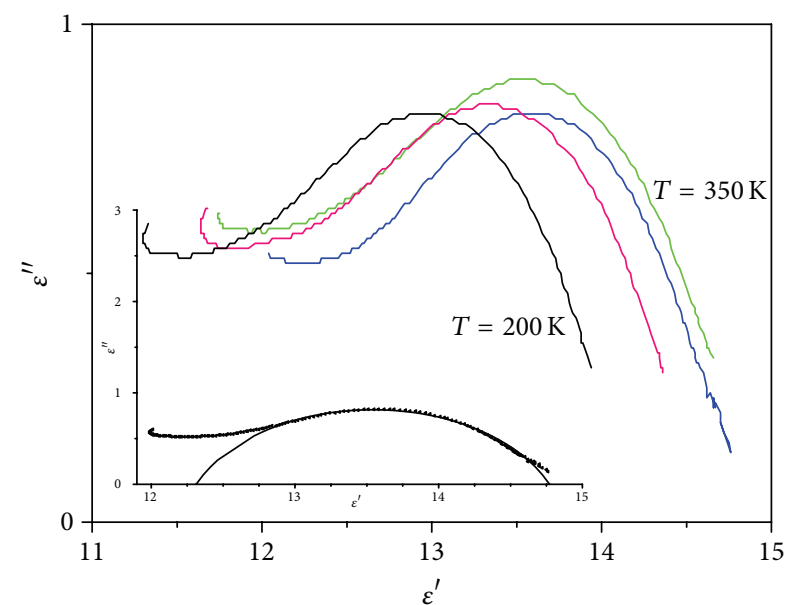

FIgURE 11: Cole-Cole plot of the complex permittivity for the same sample with concentration of $5 \mathrm{wt} . \%$ at different temperatures. The inset shows the fit.

phenomenon could be observed using DC and AC conductivity measurements and was also observed in the dielectric properties, that is, in the complex permittivity. A relaxation process was observed in all of the samples, including the neat polymer matrix; that is, this relaxation is due to the polymer and not to the fillers. The filler slightly changes this relaxation, but only very weakly. The activation energy of this relaxation process is very low. The peak in the imaginary part and the inflection in the real part of the complex permittivity do not considerably change with temperature. This result indicates that the filler does not interact or only weakly interacts with the chain segments of the macromolecules in the copolymer. This observation was also confirmed from the dynamic mechanical analysis, in which an increasing storage modulus was observed with an increasing amount of nanofiller, but no effect on the $\tan \delta$ curves was observed.

\section{Conflict of Interests}

The authors declare that there is no conflict of interests regarding the publication of this paper.

\section{Acknowledgments}

This work was supported by Bilateral Project SK-PT 002110, NMT-ERANET “APGRAPHEL," and by Project VEGA 2/0119/12. The authors would like to thank Dr. Edmund Dobrocka from the Institute of Electrical Engineering, Slovak Academy of Sciences, for XRD measurements.

\section{References}

[1] A. K. Geim and K. S. Novoselov, "The rise of graphene," Nature Materials, vol. 6, no. 3, pp. 183-191, 2007.

[2] M. S. Fuhrer, C. N. Lau, and A. H. MacDonald, "Graphene: materially better carbon," MRS Bulletin, vol. 35, no. 4, pp. 289295, 2010. 
[3] A. H. C. Neto and K. Novoselov, "New directions in science and technology: two-dimensional crystals," Reports on Progress in Physics, vol. 74, no. 8, Article ID 082501, 2011.

[4] D. R. Dreyer, R. S. Ruoff, and C. W. Bielawski, "From conception to realization: an historial account of graphene and some perspectives for its future," Angewandte Chemie-International Edition, vol. 49, no. 49, pp. 9336-9344, 2010.

[5] A. H. Castro Neto, F. Guinea, N. M. R. Peres, K. S. Novoselov, and A. K. Geim, "The electronic properties of graphene," Reviews of Modern Physics, vol. 81, no. 1, pp. 109-162, 2009.

[6] Y. Zhu, S. Murali, W. Cai et al., "Graphene and graphene oxide: synthesis, properties, and applications," Advanced Materials, vol. 22, no. 35, pp. 3906-3924, 2010.

[7] X. Huang, Z. Yin, S. Wu et al., "Graphene-based materials: synthesis, characterization, properties, and applications," Small, vol. 7, no. 14, pp. 1876-1902, 2011.

[8] X. Huang, X. Qi, F. Boey, and H. Zhang, "Graphene-based composites," Chemical Society Reviews, vol. 41, no. 2, pp. 666686, 2012.

[9] T. Kuilla, S. Bhadra, D. Yao, N. H. Kim, S. Bose, and J. H. Lee, "Recent advances in graphene based polymer composites," Progress in Polymer Science, vol. 35, no. 11, pp. 1350-1375, 2010.

[10] J. R. Potts, D. R. Dreyer, C. W. Bielawski, and R. S. Ruoff, "Graphene-based polymer nanocomposites," Polymer, vol. 52, no. 1, pp. 5-25, 2011.

[11] Z. Špitalský, C. A. Krontiras, S. N. Georga, and C. Galiotis, "Effect of oxidation treatment of multiwalled carbon nanotubes on the mechanical and electrical properties of their epoxy composites," Composites Part A: Applied Science and Manufacturing, vol. 40, no. 6-7, pp. 778-783, 2009.

[12] L. C. Costa, M. E. Achour, M. P. F. Graça, M. El Hasnaoui, A. Outzourhit, and A. Oueriagli, "Dielectric properties of the ethylene butylacrylate/carbon black nanocomposites," Journal of Non-Crystalline Solids, vol. 356, no. 4-5, pp. 270-274, 2010.

[13] M. El Hasnaoui, M. P. F. Graça, M. E. Achour et al., "Electrical properties of carbon black/copolymer composites above and below the melting temperature," Journal of Materials \& Environmental Science, vol. 2, no. 1, pp. 1-6, 2011.

[14] M. El Hasnaoui, M. P. F. Graça, M. E. Achour, and L. C. Costa, "Electric modulus analysis of carbon black/copolymer composite materials," Materials Sciences and Applications, vol. 2, no. 10, pp. 1421-1426, 2011.

[15] M. El Hasnaoui, M. P. F. Graça, M. E. Achour et al., "Effect of temperature on the electrical properties of copolymer/carbon black mixtures," Journal of Non-Crystalline Solids, vol. 356, no. 31-32, pp. 1536-1541, 2010.

[16] I. Krupa, J. Prokeš, I. Křivka, and Z. Špitalský, "Electrically conductive polymer composites and nanocomposites," in Handbook of Multiphase Polymer Systems, A. Boudenne, L. Ibos, Y. Candau, and S. Thomas, Eds., chapter 11, pp. 425-477, Wiley, 2011.

[17] S. Paszkiewicz, A. Szymczyk, Z. Špitalský et al., "Electrical conductivity of poly(ethylene terephthalate)/expanded graphite nanocomposites prepared by in situ polymerization," Journal of Polymer Science Part B: Polymer Physics, vol. 50, no. 23, pp. 1645-1652, 2012.

[18] O. Menes, M. Cano, A. Benedito et al., "The effect of ultrathin graphite on the morphology and physical properties of thermoplastic polyurethane elastomer composites," Composites Science and Technology, vol. 72, no. 13, pp. 1595-1601, 2012.
[19] J. Liang, Y. Xu, Y. Huang et al., "Infrared-triggered actuators from graphene-based nanocomposites," The Journal of Physical Chemistry C, vol. 113, no. 22, pp. 9921-9927, 2009.

[20] J. Loomis, B. King, T. Burkhead et al., "Graphene-nanoplateletbased photomechanical actuators," Nanotechnology, vol. 23, no. 4, Article ID 045501, 2012.

[21] Y. R. Lee, A. V. Raghu, H. M. Jeong, and B. K. Kim, "Properties of waterborne polyurethane/functionalized graphene sheet nanocomposites prepared by an in situ method," Macromolecular Chemistry and Physics, vol. 210, no. 15, pp. 1247-1254, 2009.

[22] D. A. Nguyen, A. V. Raghu, J. T. Choi, and H. M. Jeong, "Properties of thermoplastic polyurethane/functionalised graphene sheet nanocomposites prepared by the in situ polymerisation method," Polymers \& Polymer Composites, vol. 18, no. 7, pp. 351358, 2010.

[23] W. Zheng, X. H. Lu, and S.-C. Wong, "Electrical and mechanical properties of expanded graphite-reinforced high-density polyethylene," Journal of Applied Polymer Science, vol. 91, no. 5, pp. 2781-2788, 2004.

[24] D. Spasevska, G. P. Leal, M. Fernández, J. B. Gilev, M. Paulis, and R. Tomovska, "Crosslinked reduced graphene oxide/polymer composites via in situ synthesis by semicontinuous emulsion polymerization," RSC Advances, vol. 5, no. 21, pp. 16414-16421, 2015.

[25] T. D. Fornes and D. R. Paul, "Modeling properties of nylon 6/clay nanocomposites using composite theories," Polymer, vol. 44, no. 17, pp. 4993-5013, 2003.

[26] P. Potschke, M. Abdel-Goad, S. Pegel et al., "Comparisons among electrical and rheological properties of melt-mixed composites containing various carbon nanostructures," Journal of Macromolecular Science, Part A: Pure and Applied Chemistry, vol. 47, no. 1, pp. 12-19, 2010.

[27] G. Chen, W. Weng, D. Wu et al., "Preparation and characterization of graphite nanosheets from ultrasonic powdering technique," Carbon, vol. 42, no. 4, pp. 753-759, 2004.

[28] T. Ramanathan, S. Stankovich, D. A. Dikin et al., "Graphitic nanofillers in PMMA nanocomposites-an investigation of particle size and dispersion and their influence on nanocomposite properties," Journal of Polymer Science Part B: Polymer Physics, vol. 45, no. 15, pp. 2097-2112, 2007.

[29] L. C. Costa, A. Aoujgal, M. P. F. Graça et al., "Microwave dielectric properties of the system $\mathrm{Ba}_{1-x} \mathrm{Sr}_{x} \mathrm{TiO}_{3}$," Physica B: Condensed Matter, vol. 405, no. 17, pp. 3741-3744, 2010.

[30] H. Li, X. Zeng, and J. Guo, "Epoxidation of styrene-isoprenestyrene block copolymer and research on its reaction mechanism," Journal Wuhan University of Technology, Materials Science Edition, vol. 25, no. 3, pp. 403-407, 2010.

[31] B. J. P. Adohi, D. Bychanok, B. Haidar, and C. Brosseau, "Microwave and mechanical properties of quartz/graphenebased polymer nanocomposites," Applied Physics Letters, vol. 102, no. 7, Article ID 072903, 2013.

[32] F. Henry, Développement de la métrologie hyperfréquences et application a l'étude de l'hydratation et la diffusion de l'eau dans les matériaux macromoléculaires [Ph.D. thesis], Paris, France, 1961.

[33] I. Krupa, M. Prostredny, Z. Špitalsky, J. Krajči, and M. A. S. Almaadeed, "Electrically conductive composites based on an elastomeric matrix filled with expanded graphite as a potential oil sensing material," Smart Materials \&d Structures, vol. 23, no. 12, Article ID 125020, 2014.

[34] Z. Sun, Y. Ma, Y. Xu et al., "Effect of the particle size of expandable graphite on the thermal stability, flammability, and 
mechanical properties of high-density polyethylene/ethylene vinyl-acetate/expandable graphite composites," Polymer Engineering and Science, vol. 54, no. 5, pp. 1162-1169, 2014.

[35] L. Peponi, A. Tercjak, R. Verdejo, M. A. Lopez-Manchado, I. Mondragon, and J. M. Kenny, "Confinement of functionalized graphene sheets by triblock copolymers," The Journal of Physical Chemistry C, vol. 113, no. 42, pp. 17973-17978, 2009.

[36] S. Ansari, M. M. Neelanchery, and D. Ushus, "Graphene/ poly(styrene- $b$-isoprene- $b$-styrene) nanocomposite optical actuators," Journal of Applied Polymer Science, vol. 130, no. 6, pp. 3902-3908, 2013.

[37] B. Li and W.-H. Zhong, "Review on polymer/graphite nanoplatelet nanocomposites," Journal of Materials Science, vol. 46, no. 17, pp. 5595-5614, 2011.

[38] O. A. Al-Hartomy, A. Al-Ghamdi, N. Dishovsky et al., "Dielectric and microwave properties of natural rubber based nanocomposites containing graphene," Materials Sciences and Applications, vol. 3, pp. 453-459, 2012.

[39] O. A. Al-Hartomy, A. A. Al-Ghamdi, F. Al-Salamy et al., "Dielectric and microwave properties of graphene nanoplatelets /carbon black filled natural rubber composites," International Journal of Materials and Chemistry, vol. 2, no. 3, pp. 116-122, 2012.

[40] G. De Bellis, I. M. De Rosa, A. Dinescu, M. S. Sarto, and A. Tamburran, "Electromagnetic absorbing nanocomposites including carbon fibers, nanotubes and graphene nanoplatelets," in Proceedings of the IEEE International Symposium on Electromagnetic Compatibility (EMC '10), pp. 202-207, Fort Lauderdale, Fla, USA, July 2010.

[41] Z. Špitalský, M. Danko, and J. Mosnáček, "Preparation of functionalized graphene sheets," Current Organic Chemistry, vol. 15, no. 8, pp. 1133-1150, 2011. 

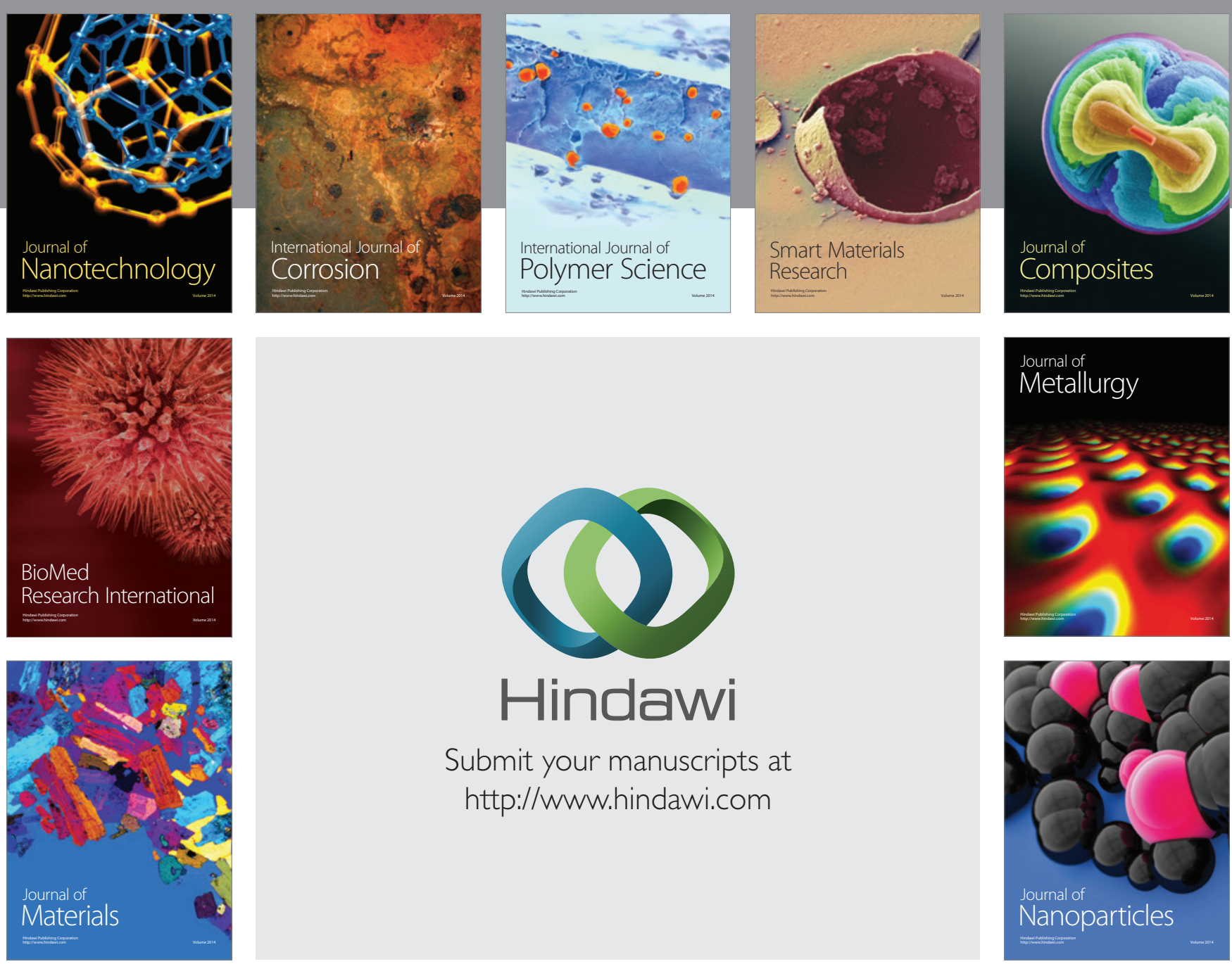

Submit your manuscripts at http://www.hindawi.com
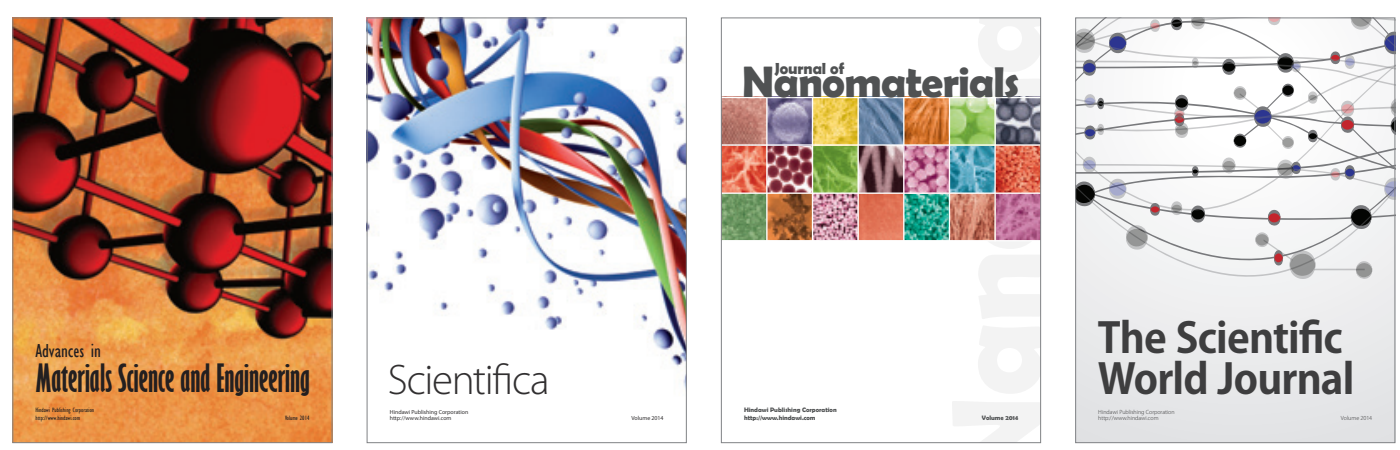

\section{The Scientific World Journal}
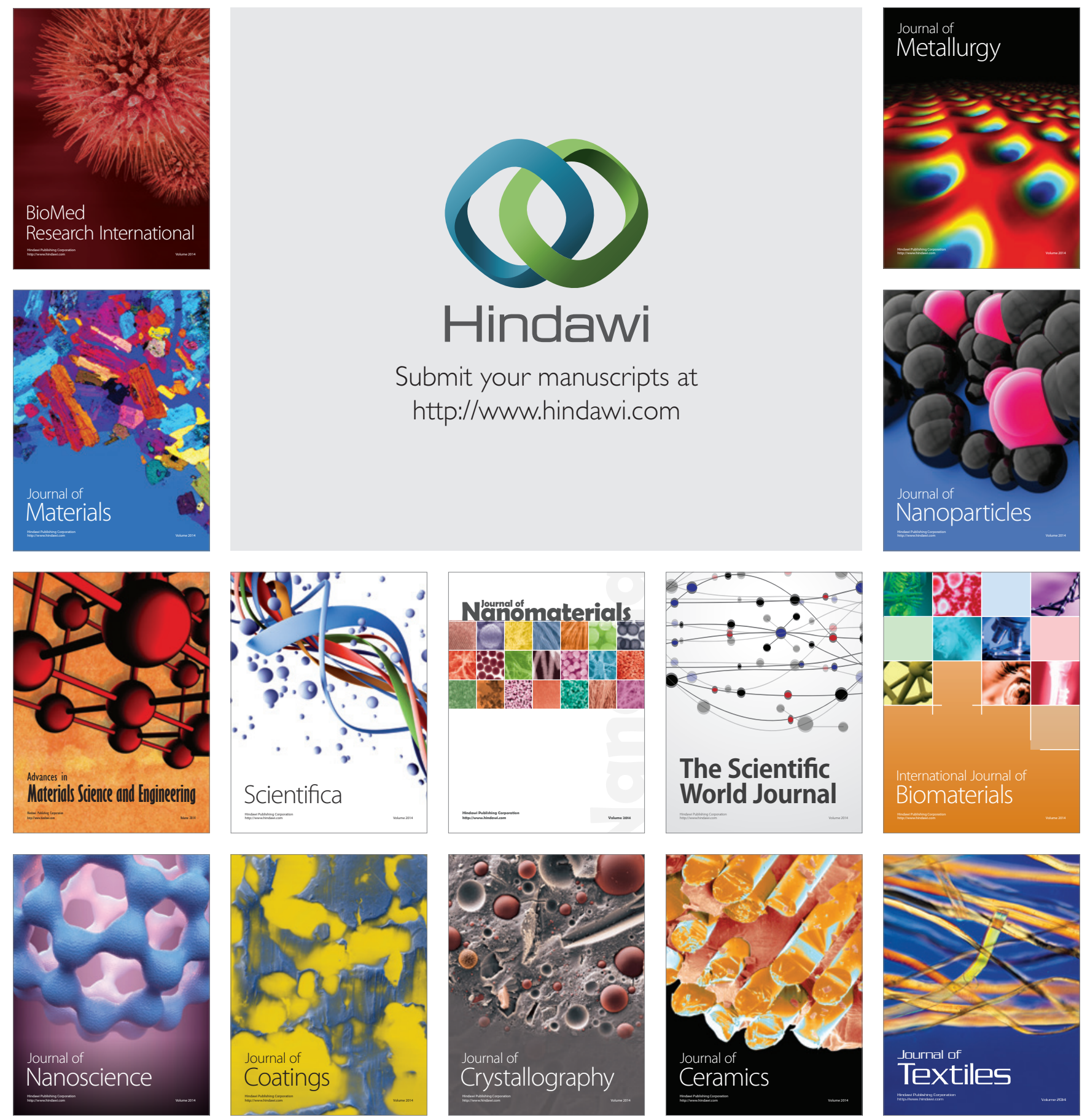